\title{
Plasma brain-derived neurotrophic factor (BDNF) in Egyptian children with attention deficit hyperactivity disorder
}

\author{
Reem El Ghamry, Mona El-Sheikh, Marwa Abdel Meguid, Safi Nagib and Dina Aly El Gabry*
}

\begin{abstract}
Background: To date, researchers do not fully understand what the aetiology of attention deficit hyperactivity disorder (ADHD) is. As a neurotrophin, the brain-derived neurotrophic factor (BDNF) contributes to the growth of neurons as well as to the efficiency and plasticity of the neuronal synapse, which suggests that it may be a contributing aetiological factor in ADHD. Therefore, we sought to investigate the relationship between ADHD and plasma BDNF, including whether there is an association between BDNF and the degree of severity of ADHD and with ADHD subtypes.
\end{abstract}

Results: We found significantly elevated plasma BDNF in ADHD subjects in comparison with healthy subjects, but differences among the three subtypes of ADHD did not reach statistical significance.

Conclusion: Compared with the control group, elevated plasma BDNF levels were found in the ADHD group, which suggests it may contribute to the aetiology of ADHD.

Keywords: Attention deficit hyperactivity disorder (ADHD), Brain-derived neurotrophic factor (BDNF), Etiology, Neurobiology

\section{Background}

Attention deficit hyperactivity disorder (ADHD) is a frequently occurring disorder with onset in childhood and one that causes stress to the individual and to families as it can adversely affect academic performance as well as economic and vocational domains [1]. Worldwide, rates of ADHD range from 3.4 to $7.2 \%[2,3]$ and in Egypt and Saudi Arabia, have reached as high as 9.4 and $11.6 \%$, respectively $[4,5]$. Its etiology, however, remains unclear [6]; although there is evidence supporting the role of the noradrenergic and dopaminergic systems [7-9]. Hence, medications that act on these systems are efficacious in the treatment of ADHD [6]. Yet, their efficacy has been called into question, as they do not address the broader clinical needs of these individuals. Therefore, traditional approaches to thinking about ADHD and its etiology are

\footnotetext{
*Correspondence: aruma99@yahoo.com

Okasha Institute of Psychiatry, Neuropsychiatry Department, Ain Shams University, Abbasiya, Cairo 1156, Egypt
}

\section{Springer Open}

being challenged and have been a focus for investigation in the field [10].

Brain-derived neurotrophic factor (BDNF) is a neurotrophin that has received attention in ADHD because of its role in synaptic efficiency and plasticity [11, 12] through its effect on the survival and differentiation of dopaminergic neurons of the midbrain [13]. In addition, BDNF has an effect on serotonergic, cholinergic, and GABAergic neurons [14], suggesting it has an association to attention and cognition [15].

BDNF gene expression has been linked to the level of serum or plasma protein in a number of psychiatric disorders [16-21], with several studies supporting BDNF's role in ADHD [8, 15, 22-25]. Serum and plasma BDNF correlate highly with their CSF levels [26]. Because circulating BDNF might originate from brain glial cells and neurons (as it crosses the blood-brain barrier bidirectionally), plasma BDNF rather than stored BDNF in the platelets better reflects the level of circulating BDNF [8].

(c) The Author(s). 2021 Open Access This article is licensed under a Creative Commons Attribution 4.0 International License, which permits use, sharing, adaptation, distribution and reproduction in any medium or format, as long as you give appropriate credit to the original author(s) and the source, provide a link to the Creative Commons licence, and indicate if changes were made. The images or other third party material in this article are included in the article's Creative Commons licence, unless indicated otherwise in a credit line to the material. If material is not included in the article's Creative Commons licence and your intended use is not permitted by statutory regulation or exceeds the permitted use, you will need to obtain permission directly from the copyright holder. To view a copy of this licence, visit http://creativecommons.org/licenses/by/4.0/. 
Changes in BDNF levels have previously been reported in ADHD [8, 24, 27-34] but findings have been mixed, with some reporting elevated BDNF in children with ADHD in comparison with control subjects [8, 30, 34], while others found no significant differences [24, 27, 29, $31,32]$ and others observing significantly lower levels of BDNF in ADHD [28, 33]. Methylphenidate is known to increase dopamine and norepinephrine signaling in the brain $[35,36]$, and both these neurotransmitters contribute to regulating BDNF expression in the hippocampus $[37,38]$. The few studies that have been conducted in Egypt investigating BDNF levels in ADHD were carried out in small samples [39-41], the largest of which included 35 subjects [40]. Therefore, we sought to carry out our study with a larger number of subjects involving 60 patients with ADHD to compare plasma BDNF levels to healthy controls. We also sought to investigate whether plasma BDNF correlated with symptom severity of the disorder.

\section{Methods \\ Participants}

Ninety participants were recruited from the Child Psychiatry outpatient department at Okasha Institute of Psychiatry, Ain Shams University, Cairo, Egypt. We divided the participants into two groups. The patient group comprised 60 drug-naïve children who have a newly received Diagnostic and Statistical Manual of Mental Disorders, 4th edition (DSM-IV) diagnosis of ADHD, between 6 and 12 years old, with an IQ of at least 90 on the Wechsler Intelligence Scale for Children (WISC), and who had no past medical history. The control group included 30 children matched for age and sex with the case group. These were healthy children recruited from children of workers at Ain Shams University Hospital. We excluded patients who had another neurodevelopmental disorder (such as Tourette's syndrome, a long-standing tic disorder, or a pervasive developmental disorder), had an IQ of less than 90, had schizophrenia or another psychotic disorder, had a longterm comorbid medical condition, or were receiving long-term medications.

\section{Tools}

We collected sociodemographic data for all participants and used the following tools:

1. Fahmi \& Sherbiny scale [42]: This was used to determine the socioeconomic status (SES) of participants, with a higher score indicating better SES. It categorized subjects into four levels: very low, low, middle, and high SES.

2. Kiddie Schedule for Affective Disorder and Schizophrenia for School-Age Children (KSADS)
[43], Arabic Version (Moussa S, Emadeldin M, Amer D, Awad MI, Ghanem M, Amin W, Zaki HS, Adel M (2011). Arabic version of Kiddie-Schedule for Affective Disorders and Schizophrenia. Unpublished manuscript- Cairo, Egypt: Cairo University): This was used to diagnose ADHD and exclude other psychiatric comorbidities. It consists of supplemental diagnostic assessments for 20 psychiatric disorders.

3. Wechsler Intelligence Scale for Children (WISC) [44]: This well-recognized tool was used to measure general intelligence and includes verbal and performance subtests, as well as an overall score for total intelligence. For our study, we used the Arabic version [45].

4. Conners' Parent Rating Scale-Revised Long Version (CPRS-R: L) [46]: This is an 80-question parentreported rating scale that assesses ADHD symptom severity. Responses are scored based on the frequency of occurrence from 0 (not true) to 3 (very true). For our study, we used the Arabic version [47].

5. Plasma BDNF Enzyme-linked immunosorbent assay (ELISA kit) [48]: The human brain-derived neurotrophic factor ELISA kit (catalog \#10186), containing an in vitro enzyme-linked immunosorbent assay, was used for the quantitative measurement of human BDNF in plasma, with a detection range of $0.5-10 \mu \mathrm{g} / \mathrm{L})$. Laboratory investigations were performed in the central laboratory of Ain Shams University Hospital under standard sanitary conditions.

\section{Procedure}

We recruited participants in the period between June, 2016 and June, 2017. The Research Ethics Committee of the Faculty of Medicine, Ain Shams University granted approval for the study (number FWA 00001785 MS 638). If subjects fulfilled the inclusion criteria and agreed to take part in the study, they were included. The purpose of the tests was fully explained to all participants. After informing them about the details of the study, we got informed written consent for taking part in the study first by asking the child's parent's permission and then, if it was appropriate for their age, by getting agreement from the participating child.

After collecting demographic data, a full physical examination was carried out to exclude any medical conditions. A full psychiatric history and examination according to DSM IV were performed using the KSADS. General intelligence was assessed using the Arabic WISC to determine eligibility for participation. Information about SES collected from one of the parents using the Fahmy and El-Sherbini scale. ADHD severity was assessed using the CPRS-RL. 
For plasma BDNF, a trained nurse, under standard conditions, collected a 5-cc blood sample from participants. Samples were transferred to the laboratory on the same day for centrifugation. Plasma was stored at -70 ${ }^{\circ} \mathrm{C}$. A trained technician carried out the analysis. The package contained 96 kits, with 6 kits used for standardization procedures and the remaining 90 kits allocated to patients (60 kits) and controls (30 kits).

\section{Laboratory procedures \\ Plasma BDNF Enzyme-linked immunosorbent assay (ELISA kit) [48]}

It contained purified human BDNF that coated the microtiter plate. Then after the formation of solid antibodies, BDNF was added to the wells. Labeled horseradish peroxidase enzyme was then combined with the BDNF antibody resulting in the formation of an antibody-antigen-enzyme complex. Addition of tetramethylbenzine then took place after complete washing. The substrate of the tetramethylbenzine then turned blue with catalyzation of the horseradish peroxidase. Adding a stop solution resulted in termination of the reaction, and a wavelength measuring $450 \mathrm{~nm}$ was used to determine the change in color. The optical density of plasma samples of study subjects was compared with a standard curve to then determine the level of BDNF for each subject.

\section{Statistical analysis}

Data were analyzed using the Statistical Package for Social Science (SPSS-20). A 0.80 power of the study was done, with calculations at $95 \%$ confidence intervals and 0.05 for $\alpha$ error. Descriptive statistics included mean and standard deviation (SD) for numerical data, and frequency and percentage of non-numerical data. Student $t$ test and analysis of variance (ANOVA) were used to compare the differences between means; chi-square was used to investigating the differences between categorical variables; Fisher's exact test was used for differences between categorical variables that had a count that was $<$ 5. Pearson's (" $r$ ") and Spearman's (" $r_{\mathrm{s}}$ ") analysis were used to assess correlations. Statistical significance was considered when $p$ values were less than 0.05 .

\section{Results}

\section{Sociodemographic features}

A total of 90 participants took part and were divided into a case group with 60 participants with ADHD and a control group of 30 matched healthy controls. Fortyfive subjects $(75.0 \%)$ of the ADHD group were males, and 15 were females (25.0\%), while 20 subjects (66.7\%) of the control group were males, and 10 (33.3\%) were females. The mean age of the ADHD group was 8.18 $(\mathrm{SD} \pm 1.61)$ years, and the mean age of the control group was $8.37(\mathrm{SD} \pm 1.79)$ years. The mean age of onset of symptoms in children with ADHD was 5.27 (SD \pm 0.71 ) years, and the mean duration of illness was 3.08 $(\mathrm{SD} \pm 1.62)$ years (Table 1$)$.

\section{Intelligence quotient (IQ) of the case and control groups} As measured by the WISC, mean total IQ of children in the ADHD group was 97.07 (SD \pm 6.01 ), mean verbal IQ was 99.13 (SD \pm 6.37 ), and mean performance IQ was 95.68 (SD \pm 8.41$)$. For the control group, the mean total intelligence quotient (IQ) of the children was 96.93 (SD $+4.67)$ as measured by the Wechsler Intelligence Scale for Children (WISC), the mean verbal IQ was 97.27 (SD \pm 5.95 ), and the mean performance IQ was 97.50 (SD \pm 7.70). No significant differences between cases and controls were found regarding total, verbal, or performance IQ $(p>0.05)$.

\section{Diagnostic subtypes of the ADHD group and severity of symptoms assessed by Conners' scale}

In terms of the distribution of diagnostic subtypes of the ADHD group, five (8.3\%) subjects had inattentive type, 15 (25\%) had hyperactive type, and 40 (66.7\%) had the combined type.

As for the severity of ADHD symptoms, our assessment in the case group using Conners' Parent Rating Scale (long version) revealed significant problems in a number of its domains. Results are as follows: oppositional (mean 67.87, SD $=10.80$ ), cognitive impairment $($ mean $=71.73, \mathrm{SD}=9.77)$, and hyperactivity $($ mean $=$ $75.6, \mathrm{SD}=10.46)$ as shown in Table 2.

\section{BDNF in healthy versus control subjects}

Comparison between children with ADHD and healthy children regarding levels of plasma BDNF $(\mathrm{ng} / \mathrm{ml})$ revealed that children with ADHD exhibit higher levels of plasma BDNF $(27.47 \pm 18.37)$ than in healthy controls $(12.30 \pm 7.17)$. This difference of levels of plasma BDNF was statistically significant (Table 3 ).

On comparing the BDNF levels between each subtype and controls, significant differences were found between the hyperactive and combined subtypes of ADHD and the control group but not between the inattentive type and controls (Table 4).

\section{Correlation BDNF with ADHD severity}

The correlation between plasma BDNF level and severity of ADHD symptoms in the ADHD group as assessed by the Conners' Parent Rating Scale showed a significant negative correlation between plasma BDNF levels and emotional lability. There were no statistically significant correlations with the remaining domains of Conner's Parent Rating Scale (Table 5). 
Table 1 Sociodemographic characteristics

\begin{tabular}{|c|c|c|c|c|}
\hline & $\begin{array}{l}\text { Cases } \\
n=60\end{array}$ & $\begin{array}{l}\text { Control } \\
n=30\end{array}$ & Test value & $p$ value \\
\hline \multicolumn{5}{|l|}{ Gender } \\
\hline Male & $45(75.0 \%)$ & $20(66.7 \%)$ & $x^{2}=0.69$ & $0.405^{(C)}$ \\
\hline Female & $15(25.0 \%)$ & $10(33.3 \%)$ & & \\
\hline \multicolumn{5}{|l|}{ Age } \\
\hline Mean & 8.18 & 8.37 & $t=0.51$ & $0.61^{(\top)}$ \\
\hline SD & 1.61 & 1.79 & & \\
\hline \multicolumn{5}{|l|}{ Body mass index } \\
\hline Mean & 16.14 & 16.22 & $t=0.36$ & $0.717^{(\mathrm{T})}$ \\
\hline SD & 1.06 & 1.03 & & \\
\hline \multicolumn{5}{|l|}{ Father's education } \\
\hline Illiterate & $3(5.0 \%)$ & $0(0.0 \%)$ & 3.46 & $0.482^{(\mathrm{F})}$ \\
\hline Primary & $3(5.0 \%)$ & $3(10.0 \%)$ & & \\
\hline Preparatory & $17(28.3 \%)$ & $11(36.7 \%)$ & & \\
\hline Secondary or technical school & $34(56.7 \%)$ & $16(53.3 \%)$ & & \\
\hline University & $3(5.0)$ & $0.00 \%$ & & \\
\hline \multicolumn{5}{|l|}{ Mother's education } \\
\hline Illiterate & $9(15.0 \%)$ & $5(16.7 \%)$ & 2.78 & $0.249^{(F)}$ \\
\hline Secondary or technical school & $46(76.7 \%)$ & 19 (63.3\%) & & \\
\hline University & $5(8.3 \%)$ & $6(20.0 \%)$ & & \\
\hline \multicolumn{5}{|l|}{ Socioeconomic class } \\
\hline Very low & $7(11.7 \%)$ & $3(10.0 \%)$ & 4.06 & $0.251^{(\mathrm{F})}$ \\
\hline Low & $13(21.7 \%)$ & $11(36.7 \%)$ & & \\
\hline Moderate & $31(51.7 \%)$ & $15(50.0 \%)$ & & \\
\hline High & $9(15.0 \%)$ & $1(3.3 \%)$ & & \\
\hline \multicolumn{5}{|l|}{ History of consanguinity } \\
\hline Yes & $10(16.7 \%)$ & $7(23.3 \%)$ & $x^{2}=0.58$ & $0.446^{(C)}$ \\
\hline No & $50(83.3 \%)$ & $23(76.7 \%)$ & & \\
\hline \multicolumn{5}{|l|}{ FH of psychiatric illness } \\
\hline Yes & $22(36.7 \%)$ & $3(10 \%)$ & $x^{2}=7.09$ & $0.008^{(C) *}$ \\
\hline No & $38(63.3 \%)$ & 27 (90\%) & & \\
\hline
\end{tabular}

${ }^{(T)} t$ test, ${ }^{(\mathrm{F})}$ Fisher's exact test, ${ }^{(\mathrm{C})}$ chi-squared test, ${ }^{*}$ statistically significant

\section{Discussion}

\section{BDNF levels in ADHD versus control groups}

Our study found that children with ADHD exhibited significantly higher levels of plasma BDNF than healthy controls. This finding is in line with Shim et al. [8] who found elevated levels of plasma BDNF in subjects with ADHD than in healthy subjects. Similar to our study, they measured plasma BDNF, with the groups matched by body mass index (BMI) and age. Similarly, the Egyptian study by Reda et al. [39] found that plasma BDNF in a group of children with ADHD was higher than in a control group of children, with the difference being statistically significant. Shim et al. [8] hypothesized that differences in BDNF levels might be due to BDNF upregulating in children with ADHD as a compensatory response for the abnormalities occurring in brain pathways involving serotonin and dopamine [8]. This is in line with Miyzaki et al. [49] who also observed significant increases of BDNF in conditions such as intellectual disability and autism spectrum disorders, in comparison with healthy participants.

Meanwhile, contrary to our findings, another Egyptian study conducted by Sayyah [41] reported that plasma BDNF in children with ADHD children was not significantly different from controls. The difference in our findings might be due to the fewer number of participants in their study, as it included 21 ADHD subjects and 20 controls. In addition, a number of ADHD cases 
Table 2 Severity of ADHD in the patient group as assessed by Conners' Parent Rating Scale

\begin{tabular}{llll}
\hline Conners' Parent Rating Scale domain & Mean & Standard deviation & Significance \\
\hline Oppositional & 67.87 & 10.80 & Clinically significant \\
Cognitive impairment & 71.13 & 9.77 & Clinically significant \\
Hyperactivity & 75.60 & 10.46 & Clinically significant \\
Anxiety-shyness & 48.43 & 4.36 & Normal \\
Perfectionism & 48.15 & 4.33 & Normal \\
Social problems & 49.23 & 4.81 & Normal \\
Psychosomatic & 48.18 & 4.31 & Normal \\
Conners' ADHD index & 72.83 & 6.90 & Clinically significant \\
Conners' index: restless-impulsive & 74.28 & 10.24 & Clinically significant \\
Conners' index: emotional lability & 67.45 & 15.05 & Clinically significant \\
Conners' global index & 70.85 & 9.77 & Clinically significant \\
DSM-IV: inattentive & 70.08 & 8.15 & Clinically significant \\
DSM-IV: hyperactivity-impulsive & 74.28 & 10.24 & Clinically significant \\
DSM-IV: total & 76.53 & 10.13 & Clinically significant \\
\hline
\end{tabular}

in their sample were already receiving treatment (unlike our study where ADHD were drug-naive), which may have influenced their outcomes [41].

On the other hand, Sargin et al. [32] and Scallestia et al. [24] found no statistically significant difference in serum BDNF levels between ADHD and control groups. The difference with our study may be due to our study measuring plasma BDNF, whereas these studies measured serum BDNF, which is about 20-fold more concentrated. It has been debated whether plasma or serum measurements are more reliable in reflecting BDNF levels in the brain, with some suggesting that it is plasma because of the minimal effect of stored platelet BDNF [8], while others support the validity of serum samples as they may reflect the role of either the illness or its treatment, during which there is an accumulation of platelet BDNF [2].

Different sampling methods and different laboratories may contribute to different results. Karege et al. [26] reported that there were variations in the level BDNF that was taken from plasma, serum or whole blood samples, according to the laboratory where the analysis was carried out. Therefore, the type of tubes in which samples are collected or the type of ELISA kit used may result to BDNF readings being different between studies.

Contrary to our results, the study in Iran by Saadat et al. [33] found significantly lower plasma BDNF levels ADHD patients compared with controls. The difference between our results and Saadat et al. may be due to the lower age range of their study which was 3.5-10 years. Different BDNF levels at different ages have been reported, with BDNF levels decreasing as age increases [49].

\section{BDNF and ADHD subtypes}

Regarding BDNF levels among different subtypes in the ADHD group, our study showed that children with attention deficit-predominant type had a lower plasma level of BDNF than children with combined type and hyperactivity-predominant type ADHD, but none of these were statistically significant differences. Similar to our finding, Sargin et al. [32] reported no significant link between the different subtypes of ADHD and serum BDNF. Saadat et al. [33] also found no significant differences in plasma BDNF levels between ADHD subtypes. On the other hand, Sayyah [41] found significantly lower plasma BDNF levels in the inattentive compared with the hyperactive type of ADHD. However, they found no significant difference between the hyperactive and combined subtypes, nor between the inattentive and combined types.

In the current study, on comparing plasma BDNF in different diagnostic categories of ADHD and controls, differences between each of the hyperactive and combined subtypes of ADHD when compared with the

Table 3 Comparison between the two studied groups regarding plasma BDNF level

\begin{tabular}{|c|c|c|c|c|c|c|c|}
\hline & \multicolumn{2}{|c|}{$\begin{array}{l}\text { Cases } \\
n=60\end{array}$} & \multicolumn{2}{|c|}{$\begin{array}{l}\text { Control } \\
n=30\end{array}$} & \multicolumn{3}{|c|}{$T$ test of significance } \\
\hline & Mean & SD & Mean & SD & $t$ & $p$ value & Sig. \\
\hline Plasma BDNF level (ng/ml) & 27.47 & 18.37 & 12.30 & 7.17 & -5.60 & $<0.001$ & Significant \\
\hline
\end{tabular}


Table 4 Comparison between plasma BDNF among control group and ADHD group; its clinical subtypes

\begin{tabular}{|c|c|c|c|c|c|}
\hline & \multicolumn{2}{|c|}{ BDNF level (ng/ml) } & \multicolumn{3}{|c|}{ ANOVA } \\
\hline & Mean & SD & $F$ & $p$ value & sig. \\
\hline \multicolumn{6}{|l|}{ Type } \\
\hline Control & 12.30 & 7.17 & 7.28 & $<0.001^{*}$ & $\mathrm{~S}$ \\
\hline Inattentive & 17.30 & 5.99 & & & \\
\hline Hyperactive & 30.63 & 18.14 & & & \\
\hline Combined & 27.55 & 19.28 & & & \\
\hline
\end{tabular}

"Post hoc test: control vs hyperactive (S) \& control vs combined (S)

control group were found which were significant, whereas there was no significant difference between the inattentive group of children and the control group. Contrary to this finding, Sayyah [41] found a significantly reduced plasma BDNF in the inattentive type of ADHD compared with the controls. Similarly, Saadat et al. [33] found that the level of plasma BDNF in the various categories of ADHD (hyperactive/impulsive, inattentive and combined) were of a significant difference in comparison to controls. The difference between our study and other studies regarding different BDNF levels between different subtypes of ADHD may be due to our sample having a small number of subjects with the inattentive type that represented only $8.3 \%$.

\section{BDNF levels and gender}

Our study found no significant differences in the levels of BDNF between males and females in either group. Findings from other studies that assessed the possible difference of BDNF level between sexes also found no differences $[8,41]$.

\section{Correlation of BDNF and ADHD symptoms}

Regarding BDNF levels and severity of ADHD symptoms, a significant negative correlation between emotional lability and BDNF was found. This might point to the fact that BDNF is highly expressed in the limbic system and the cerebral cortex, making it a mandatory factor in the regulation of affective and reward process [50]. On the other hand, research has shown that downregulation of BDNF is associated with increase in anxiety-like symptoms [51]. The exact explanation of the negative correlation between BDNF and emotional lability is not clearly understood owing to the difficulty in defining the term of emotional lability and its heterogenicity, and its amplification of an underlying complex psychopathology [52]. Otherwise, no significant correlation between BDNF levels and the scores of the remaining domains of CPRS were found. Similarly, Sargin et al. [32] found that serum BDNF and the severity of impairment due to ADHD did not significantly correlate. Similarly, Saadat et al. [33] found no significant association when correlating the level of BDNF with ADHD severity, also using the CPRS. In contrast to this finding, Shim et al. [8] observed a significant positive correlation between the severity of inattention symptoms in ADHD and the level of BDNF in the plasma. However, the process of how BDNF can affect ADHD severity is still not understood. Reda et al. [39] reported that BDNF correlated negatively with hyperactivity/impulsivity and positively with anxiety/shyness. The difference between the results of the current study and the previously discussed study is probably due to the use of different scales for assessing the severity of symptoms of ADHD. Shim and colleagues used the K-ARS (Korean

Table 5 Correlation between Conner's Parent Scale scores and BDNF level among cases

\begin{tabular}{lll}
\hline Correlation between Conners' domains with plasma BDNF levels $(\boldsymbol{\mu g} / \mathbf{L})$ & $\boldsymbol{r}$ value & $\boldsymbol{p}$ value \\
\hline Oppositional & -0.085 & 0.517 \\
Cognitive impairment & -0.086 & 0.104 \\
Hyperactivity & -0.247 & 0.427 \\
Anxiety-shyness & 0.041 & 0.057 \\
Perfectionism & 0.042 & 0.757 \\
Social problems & 0.087 & 0.749 \\
Psychosomatic & 0.022 & 0.509 \\
Conners' ADHD index & 0.118 & 0.867 \\
Conners' index: restless-impulsive & -0.353 & 0.368 \\
Conners' index: emotional lability & -0.211 & $0.006^{*}$ \\
Conners' global index & -0.095 & 0.106 \\
DSM-IV: inattentive & 0.104 & 0.469 \\
DSM-IV: hyperactivity-impulsive & 0.094 & 0.427 \\
DSM-IV: total & & 0.474 \\
\hline
\end{tabular}

*Statistically significant 
ADHD Rating scale), and Shim et al. and Reda et al. used different inclusion criteria than our study. For example, both of the previous two studies used a different threshold for IQ, where subjects were included if their IQ was $>70$, which is different to our study and may explain differences with our findings.

\section{Limitations}

Our entire case sample was selected from the Child Psychiatry Clinic, which represents cases with more severe symptoms; hence, it is difficult to generalize our results to the general population. Our study also did not investigate the effect of diet, exposure to smoking, physical activity, or any other environmental factors that might affect the BDNF levels.

In addition, our sample included a small proportion of subjects with the predominantly inattentive subtype of ADHD. Also, we did not correlate IQ data for attention and concentration with BDNF levels.

\section{Conclusions}

Children with ADHD exhibit higher levels of plasma BDNF levels in comparison with age- and sex-matched healthy controls. There is no obvious correlation between the severity of symptoms in children with ADHD and their plasma BDNF level. Our study showed that children with attention deficit-predominant type had a lower plasma level of BDNF than children with combined type and hyperactivity-predominant type ADHD yet no significant difference between subtypes of ADHD regarding BDNF level was detected. This raises the question of the possibility that drugs acting on enhancement of BDNF might play an important role in the improvement of patients with ADHD not only on symptomatic level but on the neurodevelopmental level. However, further studies are needed with larger sample sizes. However, we must take into consideration that our sample was not representative of the inattentive diagnostic subtype.

\section{Recommendations}

As BDNF plays a curial rule in neurogenesis and synaptic transmutation, further studies with larger sample sizes are needed to explore different domains concerning $\mathrm{ADHD}$ and BDNF as cognitive functions and changes to BDNF in relation to medication, as well as other psychiatric disorders as ASD and mood disorders in children. Future research should also follow up drug-naïve ADHD after different drug treatments.

\section{Abbreviations}

ADHD: Attention deficit hyperactive disorder; BDNF: Brain-derived neurotrophic factor; CPRS-RL: Conners' Parent Rating Scale -Revised Long Version; CSF: Cerebrospinal fluid; DA: Dopamine; ELISA: Enzyme-linked immunosorbent assay; IQ: Intelligence quotient; HRP: Horseradish peroxidase enzyme; The K-ARS: Korean ADHD Rating Scale; KSADS: Kiddie Schedule for Affective Disorder and Schizophrenia for School-Age Children;

NE: Norepinephrine; OD: Optical density; TMB: Tetramethylbenzine

\section{Acknowledgments}

Many thanks to the study participants.

\section{Authors' contributions}

All authors took part in the concept and study design. NMS, DHB, and AAA carried out the statistical analysis and proofread the article. YO was involved in the data collection and article's proofreading. DAE wrote-up the article and proofread it. The manuscript was approved by all authors.

Funding

No funding was received for this project.

Availability of data and materials

Available upon request

\section{Declarations}

\section{Ethics approval and consent to participate}

The study was approved by the Research Ethics Committee of the Faculty of Medicine, Ain Shams University, with ethics number FWA 00001785 MS 638. We got informed written consent for taking part in the study first by asking the child's parent's permission and then, if it was appropriate for their age, by getting agreement from the participating child.

\section{Consent for publication}

Not required

Competing interests

No conflict of interests to report

Received: 21 January 2021 Accepted: 15 March 2021

Published online: 07 May 2021

\section{References}

1. Biederman J, Faraone SV (2005) Attention-deficit hyperactivity disorder. Lancet 366(9481):237-248. https://doi.org/10.1016/S0140-6736(05)66915-2

2. Polanczyk GV, Salum GA, Sugaya LS, Caye A, Rohde LA (2015) Annual research review: a meta-analysis of the worldwide prevalence of mental disorders in children and adolescents. J Child Psychol Psychiatry 56(3):345365. https://doi.org/10.1111/jcpp.12381

3. Thomas R, Sanders S, Doust J, Beller E, Glasziou P (2015) Prevalence of attention-deficit/hyperactivity disorder: a systematic review and metaanalysis. Pediatrics 135(4):e994-e1001. https://doi.org/10.1542/peds.2014-3482

4. Bishry Z, Ramy HA, El-Shahawi HH, El-Sheikh MM, El-Missiry AA, El-Missiry MA (2014) Screening for ADHD in a sample of Egyptian adolescent school students. J Atten Disord 22(1):58-65. https://doi.org/10.1177/1087054714 533190

5. Homidi M, Obaidat $Y$, Hamaidi D (2013) Prevalence of attention deficit and hyperactivity disorder among primary school students in Jeddah city, KSA. Life Sci J 10:280-285

6. Biederman J (2005) Attention-deficit/hyperactivity disorder: a selective overview. Biol Psychiatry 57(11):1215-1220. https://doi.org/10.1016/j. biopsych.2004.10.020

7. Bonvicini C, Faraone SV, Scassellati C (2016) Attention-deficit hyperactivity disorder in adults: a systematic review and meta-analysis of genetic, pharmacogenetic and biochemical studies. Mol Psychiatry 21(7):872-884. https://doi.org/10.1038/mp.2016.74

8. Shim S-H, Hwangbo Y, Kwon Y-J, Jeong H-Y, Lee B-H, Lee H-J, Kim YK (2008) Increased levels of plasma brain-derived neurotrophic factor (BDNF) in children with attention deficit-hyperactivity disorder (ADHD). Prog Neuropsychopharmacol Biol Psychiatry 32(8):1824-1828. https://doi.org/10.1 016/i.pnpbp.2008.08.005

9. Schuch V, Utsumi DA, Costa TVMM, Kulikowski LD, Muszkat M (2015) Attention deficit hyperactivity disorder in the light of the epigenetic paradigm. Front Psychiatry 6:126. https://doi.org/10.3389/fpsyt.2015.00126 
10. Posner J, Polanczyk GV, Sonuga-Barke E (2020) Attention-deficit hyperactivity disorder. Lancet 395(10222):450-462. https://doi.org/10.1016/S0140-6736(1 9)33004-1

11. Cattaneo A, Cattane N, Begni V, Pariante CM, Riva MA (2016) The human BDNF gene: peripheral gene expression and protein levels as biomarkers for psychiatric disorders. Transl Psychiatry 6(11):e958. https://doi.org/10.1038/ tp.2016.214

12. Duman RS, Monteggia LM (2006) A neurotrophic model for stress-related mood disorders. Biol Psychiatry 59(12):1116-1127. https://doi.org/10.1016/j. biopsych.2006.02.013

13. Hyman C, Hofer M, Barde YA, Juhasz M, Yancopoulos GD, Squinto SP, Lindsay RM (1991) BDNF is a neurotrophic factor for dopaminergic neurons of the substantia nigra. Nature 350(6315):230-232. https://doi.org/10.1038/3 $50230 \mathrm{a} 0$

14. Pillai A (2008) Brain-derived neurotropic factor/TrkB signaling in the pathogenesis and novel pharmacotherapy of schizophrenia. Neurosignals 16(2-3):183-193. https://doi.org/10.1159/000111562

15. Cho S-C, Kim J-W, Kim H-W, Kim B-N, Shin M-S, Cho D-Y, Jung SW, Chung US, Son JW (2011) Effect of ADRA2A and BDNF gene-gene interaction on the continuous performance test phenotype. Psychiatr Genet 21(3):132-135. https://doi.org/10.1097/YPG.0b013e328341a389

16. Green MJ, Matheson SL, Shepherd A, Weickert CS, Carr VJ (2011) Brain-derived neurotrophic factor levels in schizophrenia: a systematic review with metaanalysis. Mol Psychiatry 16(9):960-972. https://doi.org/10.1038/mp.2010.88

17. Munkholm K, Vinberg M, Kessing LV (2016) Peripheral blood brain-derived neurotrophic factor in bipolar disorder: a comprehensive systematic review and meta-analysis. Mol Psychiatry 21(2):216-228. https://doi.org/10.1038/ mp.2015.54

18. Suliman S, Hemmings SMJ, Seedat S (2013) Brain-derived neurotrophic factor (BDNF) protein levels in anxiety disorders: systematic review and meta-regression analysis. Front Integr Neurosci 7:55. https://doi.org/10.3389/ fnint.2013.00055

19. Saghazadeh A, Rezaei N (2017) Brain-derived neurotrophic factor levels in autism: a systematic review and meta-analysis. J Autism Dev Disord 47(4): 1018-1029. https://doi.org/10.1007/s10803-016-3024-x

20. Zheng Z, Zhang L, Zhu T, Huang J, Qu Y, Mu D (2016) Peripheral brainderived neurotrophic factor in autism spectrum disorder: a systematic review and meta-analysis. Sci Rep 6(1):31241. https://doi.org/10.1038/ srep31241

21. Qin X-Y, Feng J-C, Cao C, Wu H-T, Loh YP, Cheng Y (2016) Association of peripheral blood levels of brain-derived neurotrophic factor with autism spectrum disorder in children: a systematic review and meta-analysis. JAMA Pediatr 170(11):1079-1086. https://doi.org/10.1001/jamapediatrics.2016.1626

22. Bergman O, Westberg L, Lichtenstein P, Eriksson E, Larsson H (2011) Study on the possible association of brain-derived neurotrophic factor polymorphism with the developmental course of symptoms of attention deficit and hyperactivity. Int J Neuropsychopharmacol 14(10):1367-1376. https://doi.org/10.1017/S1461145711000502

23. Lee YH, Song GG (2018) BDNF 196 G/A and COMT Val158Met polymorphisms and susceptibility to ADHD: a meta-analysis. J Atten Disord 22(9):872-877. https://doi.org/10.1177/1087054715570389

24. Scassellati C, Zanardini R, Tiberti A, Pezzani M, Valenti V, Effedri P, Filippini E, Conte S, Ottolini A, Gennarelli M, Bocchio-Chiavetto L (2014) Serum brainderived neurotrophic factor (BDNF) levels in attention deficit-hyperactivity disorder (ADHD). Eur Child Adolesc Psychiatry 23(3):173-177. https://doi. org/10.1007/s00787-013-0447-1

25. Tsai S-J (2017) Role of neurotrophic factors in attention deficit hyperactivity disorder. Cytokine Growth Factor Rev 34:35-41. https://doi.org/10.1016/j. cytogfr.2016.11.003

26. Karege F, Schwald M, Cisse M (2002) Postnatal developmental profile of brain-derived neurotrophic factor in rat brain and platelets. Neuroscience Lett 328(3):261-264. https://doi.org/10.1016/S0304-3940(02)00529-3

27. Bilgiç A, Toker A, Işık Ü, Kılınç I (2017) Serum brain-derived neurotrophic factor, glial-derived neurotrophic factor, nerve growth factor, and neurotrophin-3 levels in children with attention-deficit/hyperactivity disorder. Eur Child Adolesc Psychiatry 26(3):355-363. https://doi.org/10.1 007/s00787-016-0898-2

28. Corominas-Roso M, Ramos-Quiroga JA, Ribases M, Sanchez-Mora C, Palomar G, Valero S, Bosch R, Casas M (2013) Decreased serum levels of brainderived neurotrophic factor in adults with attention-deficit hyperactivity disorder. Int J Neuropsychopharmacol 16(6):1267-1275. https://doi.org/10.1 017/S1461145712001629

29. Cubero-Millán I, Ruiz-Ramos M-J, Molina-Carballo A, Martínez-Serrano S, Fernández-López L, Machado-Casas I, Tortosa-Pinto P, Ruiz-López A, Lunadel-Castillo JDD, Uberos J, Muñoz-Hoyos A (2017) BDNF concentrations and daily fluctuations differ among ADHD children and respond differently to methylphenidate with no relationship with depressive symptomatology. Psychopharmacology (Berl) 234(2):267-279. https://doi.org/10.1007/s00213016-4460-1

30. Li H, Liu L, Tang Y, Ji N, Yang L, Qian Q, Wang Y (2014) Sex-specific association of brain-derived neurotrophic factor (BDNF) Val66Met polymorphism and plasma BDNF with attention-deficit/hyperactivity disorder in a drug-naïve Han Chinese sample. Psychiatry Res 217(3):191-197. https://doi.org/10.1016/j.psychres.2014.03.011

31. Sahin S, Yuce M, Alacam H, Karabekiroglu K, Say GN, Salıs O (2014) Effect of methylphenidate treatment on appetite and levels of leptin, ghrelin, adiponectin, and brain-derived neurotrophic factor in children and adolescents with attention deficit and hyperactivity disorder. Int J Psychiatry Clin Pract 18(4):280-287. https://doi.org/10.3109/13651501.2014.940054

32. Sargin E, Pekcanlar Akay A, Resmi H, Alsen Cengizhan S, Özek H, Ellidokuz H et al (2012) Evaluation of serum brain-derived neurotrophic factor levels in children with attention deficit hyperactivity disorder: preliminary data. Arch Neuropsychiatry/Noropsikiatri Arsivi 49(2):96

33. Saadat F, Kosha M, Amiry A, Torabi G (2015) Brain-derived neurotrophic factor as a biomarker in children with attention deficit-hyperactivity disorder. J Krishna Inst Med Sci 4(4):10-7.

34. Zhai J, Zhang H, Xu S, Liu X, Xue B (2007) Serum brain-derived neurotrophic factor BDNF levels $V$ in attention deficit-hyperactivity disorder (ADHD). Shandong Med J 47:54-55

35. Berridge CW, Devilbiss DM, Andrzejewski ME, Arnsten AFT, Kelley AE, Schmeichel B, Hamilton C, Spencer RC (2006) Methylphenidate preferentially increases catecholamine neurotransmission within the prefrontal cortex at low doses that enhance cognitive function. Biol Psychiatry 60(10):11111120. https://doi.org/10.1016/j.biopsych.2006.04.022

36. Kuczenski R, Segal DS (2001) Locomotor effects of acute and repeated threshold doses of amphetamine and methylphenidate: relative roles of dopamine and norepinephrine. J Pharmacol Exp Ther 296:876-883

37. Miguel PM, Deniz BF, Confortim HD, de Almeida W, Bronauth LP, Vieira MC, Bertoldi K, Siqueira IR, Silveira PP, Pereira LO (2020) Methylphenidate treatment increases hippocampal BDNF levels but does not improve memory deficits in hypoxic-ischemic rats. J Psychopharmacol 34(7):750-758. https://doi.org/10.1177/0269881120913153

38. Mello-Carpes PB, Da Silva de Vargas L, Gayer MC, Roehrs R, Izquierdo I (2016) Hippocampal noradrenergic activation is necessary for object recognition memory consolidation and can promote BDNF increase and memory persistence. Neurobiol Learn Mem 127:84-92. https://doi.org/10.1 016/..nIm.2015.11.014

39. Reda M, El-Nady HG, Rabie MA, Fawzy R, Adel S, AwadAllah E et al (2016) Comparing brain-derived neurotrophic factor levels, intelligence, and memory in clinical subtypes of attention-deficit hyperactivity disorder. Middle East Curr Psychiatry 23(2):56-62. https://doi.org/10.1097/01.XME.0000481814.92893.e2

40. Taha H, Elsheshtawy E, Mohamed S, Al-Azazzy O, Elsayed M, Ibrahim SS (2017) Correlates of brain derived neurotrophic factor in children with attention deficit hyperactivity disorder: a case-control study. Egypt J Psychiatr 38(3):159. https://doi.org/10.4103/ejpsy.ejpsy_17_17

41. Sayyah H (2009) BDNF plasma level in ADHD children: correlation to different symptomatology. Curr Psychiatry [Egypt] 16:284-294

42. Fahmy S (1983) Determining simple parameters for social classifications for health research. Bull High Inst Public Health 13:95-108

43. Kaufman J, Birmaher B, Brent D, Rao U, Flynn C, Moreci P et al (1997) Schedule for affective disorders and schizophrenia for school-age childrenpresent and lifetime version (K-SADS-PL): initial reliability and validity data. J Am Acad Child Adolesc Psychiatry 36(7):980-988. https://doi.org/10.1097/ 00004583-199707000-00021

44. Wechsler D (1991) The Wechsler Intelligence Scale for children, 3rd edn. The Psychological Corporation, San Antonio

45. Ismail ME, Melika LK (1999) Wechsler Intelligence Scale for children: Arabic manual, 7th edn. El-Nahda Press, Cairo

46. Conners CK (2001) Conners rating scales, revised ed. Multi-Health Systems, North Tonawanda 
47. El Sheikh MM, Sadek A, Omar AN, El Nahass G (2003) Psychiatric morbidity in first degree relatives of a sample of ADHD children. MD thesis

48. Chul BL, Choi I-G, Kim Y-K, Ham B-J, Yang B-H, Roh S, Choi J, Lee JS, Oh DY, Chai YG (2009) Relation between plasma brain-derived neurotrophic factor and nerve growth factor in the male patients with alcohol dependence. Alcohol 43(4):265-269. https://doi.org/10.1016/j.alcohol.2009.04.003

49. Miyazaki K, Narita N, Sakuta R, Miyahara T, Naruse H, Okado N, Narita M (2004) Serum neurotrophin concentrations in autism and mental retardation: a pilot study. Brain Dev 26(5):292-295. https://doi.org/10.1016/ S0387-7604(03)00168-2

50. Lommatzsch M, Zingler D, Schuhbaeck K, Schloetcke K, Zingler C, SchuffWerner P, Virchow JC (2005) The impact of age, weight and gender on BDNF levels in human platelets and plasma. Neurobiol Aging 26(1):115-123. https://doi.org/10.1016/.j.neurobiolaging.2004.03.002

51. Murinova J, Hlavacova N, Chmelova M, Riečanský I (2017) The evidence for altered BDNF expression in the brain of rats reared or housed in social isolation: a systematic review. Front Behav Neurosci 11:101. https://doi.org/1 0.3389/fnbeh.2017.00101

52. Moukhtarian TR, Cooper RE, Vassos E, Moran P, Asherson P (2017) Effects of stimulants and atomoxetine on emotional lability in adults: a systematic review and meta-analysis. Eur Psychiatry 3527:1-10

\section{Publisher's Note}

Springer Nature remains neutral with regard to jurisdictional claims in published maps and institutional affiliations.

\section{Submit your manuscript to a SpringerOpen ${ }^{\circ}$ journal and benefit from:}

- Convenient online submission

- Rigorous peer review

- Open access: articles freely available online

High visibility within the field

- Retaining the copyright to your article

Submit your next manuscript at $\boldsymbol{\nabla}$ springeropen.com 